\title{
Uncertainty Instability Risk Analysis of High Concrete Arch Dam Abutments
}

\author{
Xin Cao, ${ }^{1,2}$ Chongshi Gu, ${ }^{1,2}$ and Erfeng Zhao ${ }^{1,2}$ \\ ${ }^{1}$ State Key Laboratory of Hydrology-Water Resources and Hydraulic Engineering, Hohai University, Nanjing 210098, China \\ ${ }^{2}$ National Engineering Research Center of Water Resources Efficient Utilization and Engineering Safety, Hohai University, \\ Nanjing 210098, China \\ Correspondence should be addressed to Xin Cao; cx_hhu@outlook.com
}

Received 1 August 2017; Revised 29 August 2017; Accepted 5 September 2017; Published 12 October 2017

Academic Editor: Roman Wendner

Copyright (C) 2017 Xin Cao et al. This is an open access article distributed under the Creative Commons Attribution License, which permits unrestricted use, distribution, and reproduction in any medium, provided the original work is properly cited.

\begin{abstract}
The uncertainties associated with concrete arch dams rise with the increased height of dams. Given the uncertainties associated with influencing factors, the stability of high arch dam abutments as a fuzzy random event was studied. In addition, given the randomness and fuzziness of calculation parameters as well as the failure criterion, hazard point and hazard surface uncertainty instability risk ratio models were proposed for high arch dam abutments on the basis of credibility theory. The uncertainty instability failure criterion was derived through the analysis of the progressive instability failure process on the basis of Shannon's entropy theory. The uncertainties associated with influencing factors were quantized by probability or possibility distribution assignments. Gaussian random theory was used to generate random realizations for influence factors with spatial variability. The uncertainty stability analysis method was proposed by combining the finite element analysis and the limit equilibrium method. The instability risk ratio was calculated using the Monte Carlo simulation method and fuzzy random postprocessing. Results corroborate that the modeling approach is sound and that the calculation method is feasible.
\end{abstract}

\section{Introduction}

The antisliding stability of dam abutments is critical in ensuring the safety of high concrete arch dams, which are faced with complex geological conditions, such as soft rock strata and fault fracture zone, as well as impacted by multiple loads, such as water pressure, silt pressure, temperature load, and seismic load [1]. The safety coefficient of an antisliding stability method is mostly commonly used in traditional methods for concrete arch dams, among which overload safety and strength reduction safety coefficients are widely used in the design as well as safety evaluation of dams. However, given the influence of uncertainties associated with material property, load, geometrical size, and failure criterion, the safety coefficients of arch dam abutments are actually uncertain variables with certain probabilities.

A risk analysis method can effectively reflect the stability safety degree of high concrete dams associated with complex uncertainties. Notably, the process of arch dam abutment failure is divided into the following three stages [2]: (1) the elastic stage, (2) the yield stage, and (3) the bearing capacity lost stage. This process develops gradually from local to global, with no clear boundary among different stages. The complex geological conditions of high concrete dams lead to the fuzziness of rock division as well as the randomness and spatial variation of mechanical parameters of rock and soil $[3,4]$. Given the monitoring error and the fluctuation of themselves, the water pressure, dead load, silt pressure, and seepage pressure acting on high concrete dams are associated with uncertainties [5]. Certain loads, such as dead and temperature drop loads, are beneficial to antisliding stability [6], in which seeking out the adverse combination of loads by adopting the probabilistic risk analysis method is possible. Through appropriate probability and possibility assignments for uncertainty variables as well as the use of fuzzy random theory, the aforementioned uncertainties can be analyzed simultaneously with risk models to reflect the actual status of instability of high concrete arch dam abutments. 
With the construction of a group of 300-meter-level ultrahigh arch dams in China, research on the failure mechanism and simulation analysis about the antisliding stability analysis of high concrete arch dam abutments has gained considerable attention among many researchers [7-10]. The current research on dam abutment antisliding stability falls into the following two categories: (1) the rigid body method and (2) the deformable body method [11]. The former obtains antislide stability safety coefficient through a comparison of shear resistance strength with shear force on the sliding surface, whereas the latter applies the simulation analysis method to obtain the stress and strain distribution, thereby qualitatively analyzing the system stability as well as quantitatively giving out the stability safety degree. However, faced with a special service environment, such as high water level, high seepage pressure, and complex geological conditions, the uncertainties associated with high concrete arch dams significantly rise with the increased height of dams. The real antisliding stability state cannot be comprehensively reflected in a single analysis method. Therefore, combining several methods and proposing a novel analysis method that can take complex uncertainties into full consideration are crucial.

In this study, using credibility theory $[12,13]$, the credibility risk analysis model of dam abutments is proposed on the basis of comprehensive identification on the uncertainties associated with high concrete arch dam abutments. The stress and strain distribution obtained by the finite element method (FEM) is plugged into the rigid body limit equilibrium method and combined with a Gaussian random field (GRF) model and Monte Carlo simulation (MCS), thereby proposing the hazard point instability risk and hazard surface instability risk models.

\section{Instability Risk Analysis of High Concrete Arch Dam Abutments}

2.1. Instability Risk Ratio Model. According to different calculation scales and targets, instability risk ratio can be divided into the following two categories: (1) hazard point risk ratio and (2) hazard surface risk ratio. The stability of high concrete arch dam abutments regarded as a fuzzy random event, the imposed loads (such as water pressure, silt pressure, temperature, and seepage pressure), the material properties of dam body and foundation (such as unit weight of concrete, unit weight of rock, cohesion, and fiction coefficient), and geometrical parameters (such as rock division and size of slide mass) are considered as independent random variables or fuzzy variables; the slide surface is considered as the calculation object; and the hazard surface instability risk ratio model is established as follows:

$$
\widetilde{P}=\int_{-\infty}^{+\infty} F(Z) \varphi_{s}(Z) d Z,
$$

where $F(Z)$ is the cumulative credibility distribution function of the fuzzy failure criterion; $F(Z)=\int_{Z}^{+\infty} f(Z) d Z$, $f(Z)$ is the credibility density function of the fuzzy failure criterion; and $\varphi_{s}(Z)$ is the credibility density function of the instability state of the slide surface. Instability state functions
$\left(Z=g\left(X_{1}, X_{2}, \ldots, X_{n}\right), X_{1}, X_{2}, \ldots, X_{n}\right)$ are dam body and foundation parameters, such as load, material properties, and geometrical size.

Given the spatial variation of rock and soil mechanical parameters on the slide surface (the instability state function of the $i$ th calculation point being $Z_{i}$ ) as well as the investigation of the distribution of $Z_{i}$ on the slide surface, the hazard point instability risk ratio model is proposed as follows:

$$
\widetilde{P}=\int_{-\infty}^{+\infty} F(Z) \varphi_{p}(Z) d Z,
$$

where $\varphi_{p}(Z)$ is the density function of instability state distribution and $\Phi_{p}(Z)$ is the corresponding cumulative function, which is the ratio of calculation points on the slide surface where the instability state function $Z_{i}$ satisfies $Z_{i} \leq Z$ : namely, $\Phi_{p}(Z)=n / N$, where $n$ is the number of calculation points on the surface which satisfy $Z_{i} \leq Z$ and $N$ is the total number of calculation points on the slide surface.

2.2. Uncertainty Stability Analysis Method of Arch Dam Abutments. The traditional stability analysis methods of arch dam abutments are classified into the following two main categories: (1) rigid body method and (2) deformable body method [11].

With the use of the rigid body method, mechanical and deformable simplification assumptions are carried out on the calculation objects (slide surfaces or blocks). Internal forces are obtained according to static force equilibrium. Subsequently, the factors of antisliding stability safety can be obtained from the ratio of the shear strength to the shear force of slide blocks or slide surfaces. The expression is as follows:

$$
K=\frac{\sum(N f+c A)}{\sum T},
$$

where $N$ and $T$ are the normal force and the tangential force on the calculation surfaces, respectively, $f$ and $c$ are the friction coefficient and the cohesion, respectively, and $A$ is the area of the slide surface. This method has an advantage of definite conception, allows simple calculation, and is fully proven by engineering practices. However, this method is associated with the following disadvantages: (1) this method considers equilibrium condition alone, without considering deformation compatibility conditions as well as material constitutive relationships, and (2) the computation is unique and precise only if the slide surfaces are flat or if the arc surfaces are given in advance.

The deformable body method uses FEM simulation analysis to determine the stress and strain distribution of dam body and foundation, qualitatively analyzes the stability, and quantitatively gives out the overall stabilization safety degree for high concrete arch dams. According to the linear elastic results of FEM calculation, the point safety factor of each calculation point on the hazard surfaces can be obtained with the application of Mohr-Coulomb formula $k=\left(f \sigma_{n}+\right.$ $c) / \tau_{t}$. Dam abutment stability can be determined according to the value and distribution of point safety factors. On the basis of elastic-plastic calculation results, dam abutment stability can be evaluated by investigating the plastic zone and 


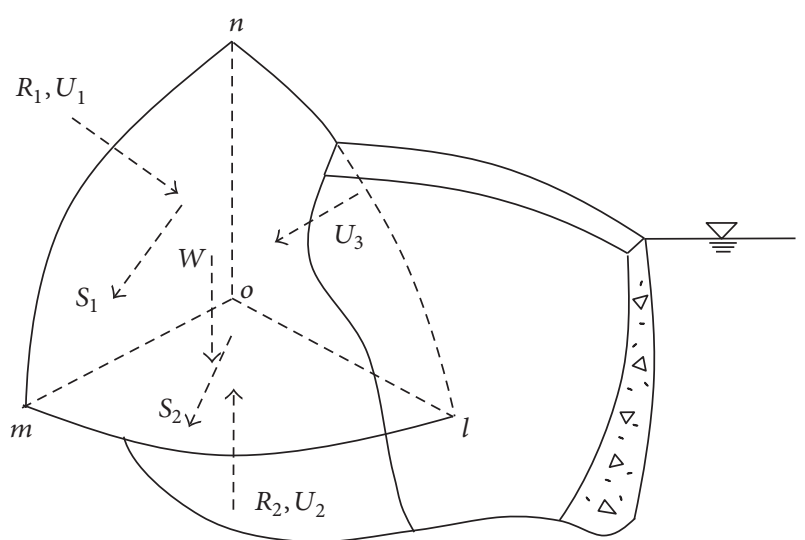

FIGURE 1: Force diagram of the antisliding stability analysis of arch dam abutments.

the crack area on the slide surfaces. The deformable body method considers the constitutive model and deformation compatibility conditions that are close to the actual operation status [14].

The uncertainty stability analysis methods of arch dam abutments, which consider hazard points and hazard surfaces as the computing objects as well as considering deformation compatibility conditions and parameter uncertainties, are established as follows.

According to the hazard point instability risk ratio model, the stability state function of calculation points can be obtained by plugging the stress computation results and assignments of material parameters into the Mohr-Coulomb formula [15].

$$
Z_{i}=\frac{f_{i} \sigma_{n i}+c_{i}}{\tau_{t i}},
$$

where $f_{i}$ and $c_{i}$ are the friction coefficient and the cohesion of the $i$ th calculation point, respectively; $\sigma_{n i}$ is the normal stress; and $\tau_{t i}$ is the tangential stress. Gaussian random field theory is used to generate random realizations for the hazard surfaces with values of $f_{i}$ and $c_{i}$ at each calculation point on the hazard surfaces.

In the hazard surface instability risk ratio model, the forces on the block are as follows: normal force $R_{1}$, shear force $S_{1}$, and seepage pressure $U_{1}$ on the side slide surface nom as well as normal force $R_{2}$, shear force $S_{2}$, and seepage pressure $U_{2}$ on the bottom slide surface lom (see the force diagram in Figure 1). The total weight of the calculation block, including dam body and foundation, is $W, W=W_{1}+W_{2}$, where $W_{1}$ is the sum of dam body weight as well as water weight and $W_{2}$ is the weight of the wedge block. According to the FEM and limit equilibrium theory, the instability state function is established as follows:

$$
Z=\frac{f_{1}\left(R_{1}-U_{1}\right)+f_{2}\left(R_{2}-U_{2}\right)+c_{1} A_{1}+c_{2} A_{2}}{S_{1} \cos \alpha_{1}+S_{2} \cos \alpha_{2}},
$$

where $f_{1}, c_{1}$, and $A_{1}$ are the friction coefficient, the cohesion, and the area of the side slide surface nom, respectively, where $f_{2}, c_{2}$, and $A_{2}$ are friction coefficient, the cohesion, and the area of the bottom slide surface lom, respectively, as well as where $\alpha_{1}, \alpha_{2}$ are the angles between the shear forces $\left(S_{1}\right.$ and $\mathrm{S}_{2}$ ) and the intersection (om).

Seepage pressure is considered to reduce triangularly from full head to zero from the upstream of the wedge to the edge of both slide surfaces. The calculation formula of $U_{1}, U_{2}$ is as follows:

$$
\begin{aligned}
& U_{1}=\frac{\beta A_{1} h}{3} \\
& U_{2}=\frac{\beta A_{2} h}{3},
\end{aligned}
$$

where $\beta$ is the uplift pressure coefficient, generally between 0.3 and 0.5 , as well as where $h$ is the full head at the wedge tip (o).

With the use of the uncertainty stability analysis method, the potential slide surfaces and slide blocks are determined by yield zone connection from nonlinear finite element computation. The load factors of the computing object are given by finite element results, and the rest of the parameters are given by fuzzy random assignments or GRF simulation.

2.3. Uncertainty Identification of the Risk Factors of Dam Abutment Instability. The risk factors of dam abutment instability mainly contain calculation parameter uncertainties and geometrical size uncertainties. The calculation parameters consist of loads and material properties. Influenced by subjective and objective factors, such as fluctuating environments and monitoring errors, uncertainties associated with the concentrated and distributed forces (such as water pressure, seepage pressure, and silt pressure) on the dam body as well as foundation of high concrete arch dams exist. The friction coefficient and cohesion in dam body and foundation as well as on structural surfaces also contain randomness or fuzziness. Therefore, these loads and material properties can be regarded as random or fuzzy variables with certain probability or possibility. The geometrical uncertainties mainly resulted from rock division, rock mass structure, and the position of the slide surface as well as the slide mode. Therefore, the geometrical parameters in the stability analysis model may be regarded as random or fuzzy variables.

In addition, the spatial variability of rock and soil mechanical parameters plays an important role in the instability risk analysis of dam abutments. The rock mass of dam foundation is conventionally divided into several equivalent continuous areas, and material properties are given a unique value in each area. However, influenced by lithological characters, rock structures, and the supporting environment, the rock and soil mechanical parameters of dam foundation possess a significant feature of spatial variability [4]. In this study, the distribution of mechanical parameters in dam abutments is regarded as a GRF. The correlation coefficient of a certain random parameter $[X=X(x, y)]$ between two points $[(x, y)]$ and $[(x+\Delta x, y+\Delta y)]$ defined in the same 
domain that are, respectively, $\Delta x$ and $\Delta y$ apart in horizontal and vertical direction is [16]

$$
\begin{aligned}
\rho[X(x, y), X(x+\Delta x, y+\Delta y)] \\
\quad=\frac{C[X(x, y), X(x+\Delta x, y+\Delta y)]}{\sigma_{X}^{2}} \\
\quad=\frac{E\left\{\left[X(x, y)-\mu_{X}\right]\left[X(x+\Delta x, y+\Delta y)-\mu_{X}\right]\right\}}{\sigma_{X}^{2}} .
\end{aligned}
$$

A fast Fourier transform (FFT) technique is used to generate isotropic GRFs for mechanical properties. The onesided spectral density function for single exponential correlation coefficient is defined as [17]

$$
G\left(\omega_{1}, \omega_{2}\right)=\frac{\sigma^{2} \theta_{1} \theta_{2}}{\pi^{2}\left[1+\left(\theta_{1} \omega_{1} / 2\right)^{2}\right]\left[1+\left(\theta_{2} \omega_{2} / 2\right)^{2}\right]} .
$$

2.4. Failure Criterion of Dam Abutment Instability. The instability of high concrete arch dam abutments is a gradual process from local to global. The results confirm that the instable failure of high arch dams is mainly caused by the existing defects in the base or near the foundation surface, which cause stress concentration at certain areas of dam body and foundation, especially at the upstream dam heel and weak structure surface of the base, thereby leading to local yielding as well as cracking and then gradually extending and resulting in the global instable failure [18]. An extreme point on the stress-strain curve exists; hence, the following instability criteria can be adopted [11]:

(1) Convergence Criterion. The instability of strength belongs to an extreme point type that has an extreme point on its loaddeformation curve, which can be reflected on calculation that iteration is not convergent. Therefore, during the elasticplastic analysis, after ruling out other reasons, the iteration nonconvergence caused by the excessive development of plastic zones can serve as system instability failure criterion.

(2) Catastrophe Criterion. A certain system is in a state of limit equilibrium, that is, transforming from the equilibrium state to another state, which means that catastrophe appears in the system. In the catastrophe criterion, any phenomenon that reflects system state catastrophe (such as the sudden increase of displacement and the connection of yield zones) can be regarded as the instability criterion.

In this study, the uncertainty instability criterion function of high concrete arch dams is proposed on the basis of the catastrophe criterion. According to previous analysis, the instability failure of arch dams is a gradual course without a clear dividing limit among different states. For example, in the conventional overload method when overload factor $Z$ exceeds a certain threshold $\left(Z_{0}\right)$, the dam abutment is considered to have reached the catastrophe point; hence, the stability safety coefficient is determined as $Z_{0}$ (see the displacement-overload factor curve in Figure 2). In fact, the system should not be deemed absolutely safe when overload factor $Z$ is less than the critical value $\left(Z_{0}\right)$ or inevitably

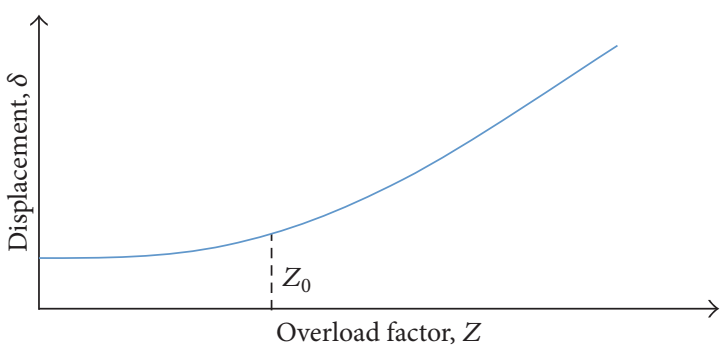

Figure 2: Displacement-overload factor curve.

instable if $Z$ continues increasing after exceeding $Z_{0}$. The same is true for the yield connection method or the strength reduction method. The determination of critical value for the stability safety of high arch dams is a subjective process of judgment, which is, substantially, a fuzzy variable with certain possibility. The possibility distribution of this fuzzy variable is defined as the instability failure criterion distribution function $[f(Z)]$.

$f(Z)$ can be obtained using the maximum entropy method. The Shannon entropy [19], which is introduced to describe the uncertainties in the dam abutment instability failure criterion, is

$$
H(Z)=-\int f(Z) \ln f(Z) d Z
$$

The generalized weighted distance $[D(Z)]$, which represents the distance between a certain stability state function $(Z)$ and the extreme point $\left(Z_{m}\right)$, is as follows:

$$
D(Z)=\beta_{1} f(Z)\left|Z_{m}-Z\right|,
$$

where $Z_{m}$ is the stability state function value at the extreme point, $Z$ is the stability state function value, and $\beta_{1}$ is the distance coefficient.

The determination of $f(Z)$ should maximize the Shannon entropy $[H(Z)]$ and minimize the generalized weighted distance $[D(Z)]$. The expressions are as follows:

$$
\begin{array}{ll}
\max _{f(Z)} & H=-\int_{-\infty}^{+\infty} f(Z) \ln f(Z) d Z \\
\min _{f(Z)} & D=\int_{-\infty}^{+\infty} \beta_{1} f(Z)\left|Z_{m}-Z\right| d Z \\
\text { s.t. } & \int_{-\infty}^{+\infty} f(Z) d Z=1
\end{array}
$$

which is a multiobjective programming problem that can be replaced by a single objective programming problem using a weighting method,

$$
\begin{aligned}
\min _{f(Z)} \quad Y=D-\frac{1}{\eta} H \\
=\int_{-\infty}^{+\infty}\left\{\beta_{1} f(Z)\left|Z_{m}-Z\right|+\frac{1}{\eta} f(Z) \ln f(Z)\right\} d Z \\
\text { s.t. } \quad \int_{-\infty}^{+\infty} f(Z) d Z=1,
\end{aligned}
$$


where $\eta$ is the weighting factor. The optimal solution must satisfy the Kuhn-Tucker condition.

The uncertainty instability failure criterion distribution function obtained by using the Lagrangian multiplier method is

$$
f(Z)=\frac{\exp \left(-\eta \beta_{1}\left|Z_{m}-Z\right|\right)}{\int_{-\infty}^{+\infty} \exp \left(-\eta \beta_{1}\left|Z_{m}-Z\right|\right) d Z}
$$

of which the integral on the interval $[Z,+\infty]$ defined as the instability failure criterion cumulative distribution function is

$$
F(Z)=\frac{\int_{Z}^{+\infty} \exp \left(-\eta \beta_{1}\left|Z_{m}-Z\right|\right)}{\int_{-\infty}^{+\infty} \exp \left(-\eta \beta_{1}\left|Z_{m}-Z\right|\right) d Z}
$$

2.5. Limit State Fuzzy Random Simulation. In this study, the correlative factors other than spatial variability are not considered. Moreover, the GRFs are considered weakly stationary. Accordingly, the following assumptions are made: (1) different random and fuzzy factors are independent; (2) the expected value (mean) and variance are similar at every point within the region of the definition of the random field; and (3) a correlation coefficient function governs the degree of correlation between the residuals of any two points in the domain.

Based on these assumptions, in the fuzzy random simulation, certain variables were, initially, vested with a random distribution, and others were given with a possibility distribution. If the model contains $k$ random variables $\left(X_{1}, X_{2}, \ldots, X_{k}\right)$ and $n-k$ fuzzy variables $\left(X_{k+1}, X_{k+2}, \ldots, X_{n}\right)$. Subsequently, utilizing the level-set algorithm proposed in [20], $M$ level sets were taken for the $n-k$ fuzzy variables, and MCS was taken $N$ times for $k$ random variables. Therefore, $M \times N$ fuzzy random responses were generated. Finally, by carrying out the postprocessing through chance combination theorem $\operatorname{Ch}\{X \times Y\}=\operatorname{Cr}\{X\} \wedge \operatorname{Pr}\{Y\}$, the credibility fuzzy random responses were obtained (Figure 3$). \mu_{i}(Z)$ is the fuzzy response curve of the $i$ th random sample, and $\Phi_{i}(Z)$ is the corresponding credibility fuzzy random response curve.

Specifically, a GRF is applied to simulate the spatial variability of rock and soil parameter on the slide surface in the hazard point risk model. When the GRF is generated, each point on the slide surface is vested with a random value. Therefore, MCS is repeated $N=N_{P} \times N_{G}$ times here, where $N_{P}$ and $N_{G}$ are the calculation point numbers on the slide surface and GRF simulation times, respectively.

2.6. Calculation of Instability of High Arch Dam Abutments. The calculation of the instability risk ratio of high arch dam abutments is a complex process, which is divided into the following three main stages: (1) carry out fuzzy random simulation for influence factors using MCS as well as GRF, (2) solve the function expression of $f(Z)$, and (3) obtain the risk

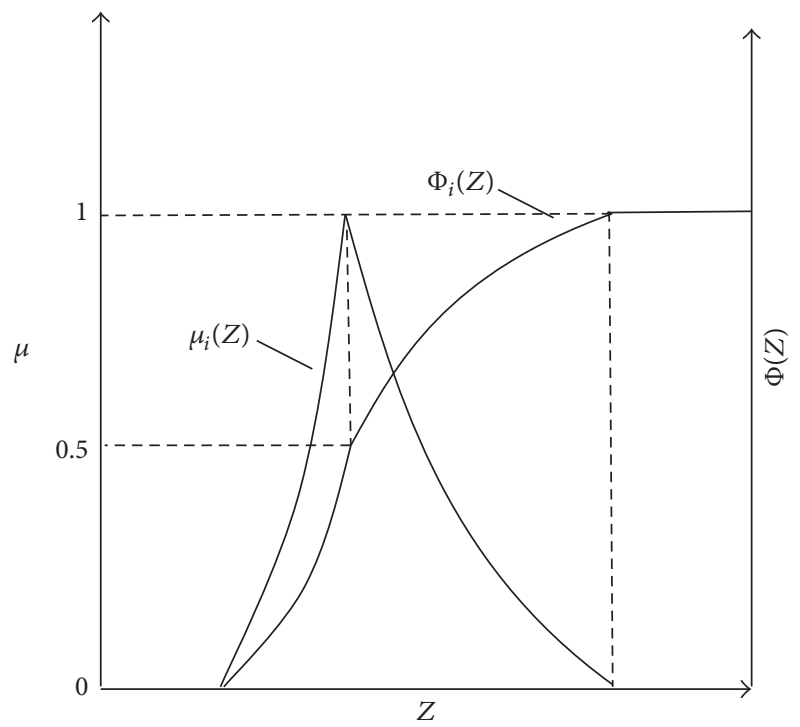

FIGURE 3: Credibility fuzzy random responses.

ratio $(\widetilde{P})$ by conducting postprocessing on the fuzzy random simulation response as well as by plugging $F(Z)$ and $\varphi(Z)$ into the instability risk ratio models.

Concrete steps are as follows.

Step 1. Establish a finite element model. Calculate the stressstrain distribution under elastoplastic conditions.

Step 2. Find the potential failure surfaces according to the connection of the yield zone.

Step 3. Determine probability and possibility distributions for parameters on the basis of risk factor identification. Generate a GRF for geomechanical properties using the FFT technique.

Step 4. On the basis of force analysis, establish the stability state function $\left[Z=g\left(X_{1}, X_{2}, \ldots, X_{n}\right)\right]$.

Step 5. Get the fuzzy random simulation response using the MCS method.

Step 6. Carry out postprocessing on the fuzzy random simulation response, and get the cumulative credibility distribution of high arch dam instability.

Step 7. Obtain the displacement-safety coefficient curve or the yield volume ratio-safety coefficient curve (safety coefficient corresponding to overload coefficient or strength reduction coefficient). On this basis, solve the instability failure criterion function $[f(Z)]$ according to the maximum entropy principle.

Step 8. Calculate the instability risk ratio $(\widetilde{P})$ for high arch dams on the basis of instability risk models, instability failure criterion distribution function, and cumulative credibility distribution. 


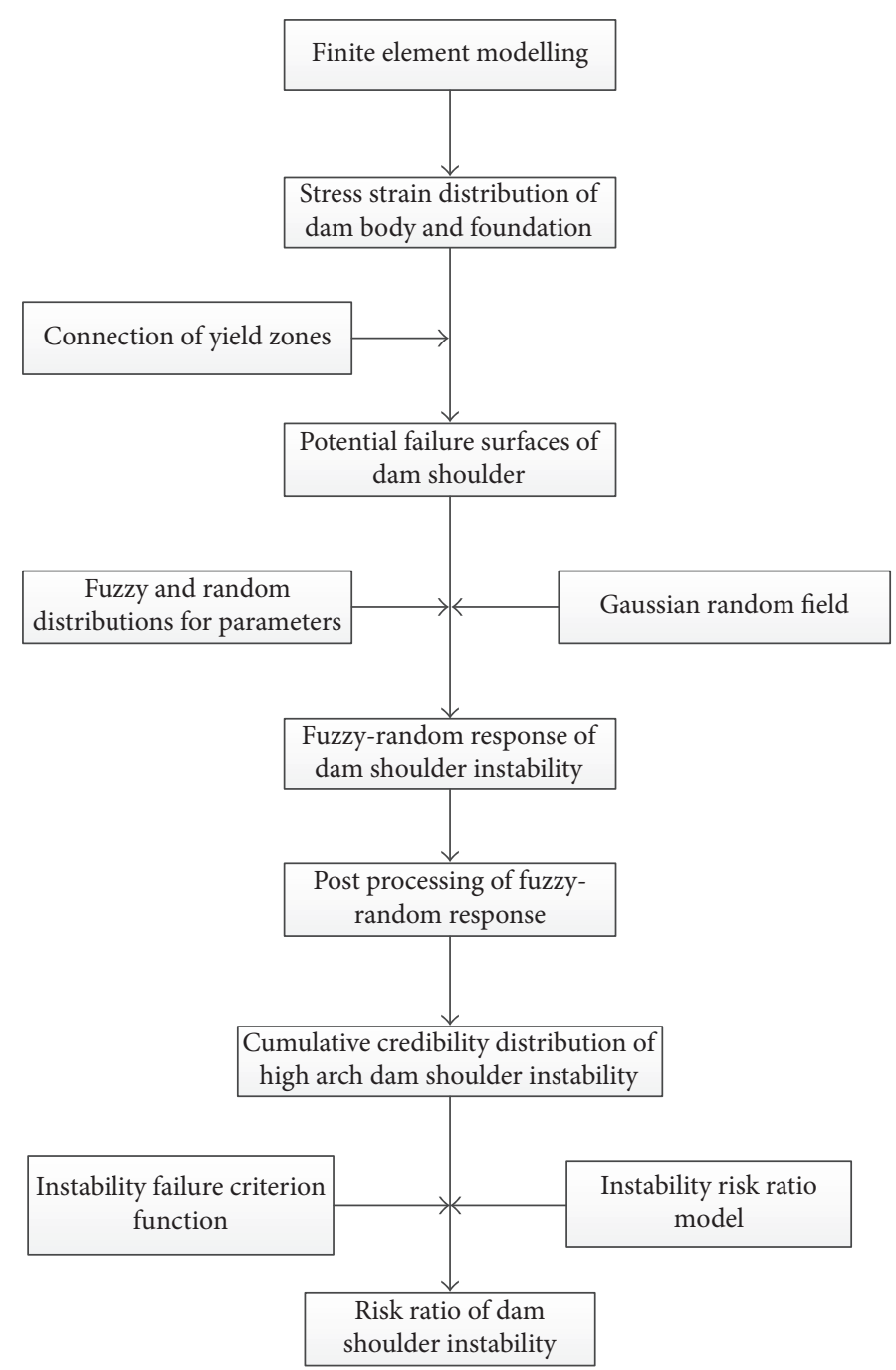

FIGURE 4: Algorithm of instability risk ratio calculation for high arch dam abutments.

\section{Case Study}

A concrete arch dam is located in southwest China. The crest elevation is $1885.0 \mathrm{~m}$, the minimum foundation surface is $1580.0 \mathrm{~m}$, and the maximum dam height is $305.0 \mathrm{~m}$. The normal water level is $1880 \mathrm{~m}$. The engineering geologic conditions of dam foundation are good. The dam site is mainly composed of marble, and sand slate only appears partly on the upper part of the left bank. The main faults at the dam site are $\mathrm{f} 2, \mathrm{f} 5, \mathrm{f} 8, \mathrm{f} 38-6$, and $\mathrm{f} 42-9$ on the left bank and $\mathrm{f13}, \mathrm{f14}$, and $\mathrm{f} 18$ on the right bank. In this case, the left bank abutment is regarded as the analysis object, and the instability risk ratio is calculated by FEM analysis and the risk analysis method.

3.1. FEM Simulation. The finite element model that simulates the dam body and foundation structure, rock division, and main faults is established. The established finite element model is composed of 923737 elements and 957221 nodes, among which 29840 elements and 36079 nodes are for the dam body. The coordinate selection of the model is that the $x$ axis is perpendicular to the dam center line, with the positive direction pointing to the left bank $\left(\mathrm{SE} 62^{\circ}\right)$, and the $y$-axis is parallel to the dam center line, with the positive direction pointing to the downstream $\left(\mathrm{NE} 28^{\circ}\right)$. The computed region is that the left and right boundaries are $900 \mathrm{~m}$ apart from the dam center line; the upstream and downstream boundaries are $750 \mathrm{~m}$ apart from the dam crest origin; the lower boundary is $700 \mathrm{~m}$ below the minimum foundation surface; and the rock slope above the crest elevation is cut to the natural boundary elevation. For the mountains on the left and right banks, the computed region extends 2.5 times the dam height upstream and downstream as well as 1 time the dam height upward. The rock mass conditions after the excavation as well as the mountain shape are simulated. Figure 4 exhibits the model.

Figure 5 depicts the material partition of the dam body. The material properties of other parts refer to the geological 
TABLE 1: Geological suggestion mean values of rock groups and structural surfaces.

\begin{tabular}{|c|c|c|c|c|c|}
\hline Material class & $E(\mathrm{GPa})$ & $u$ & $\rho\left(\mathrm{kN} / \mathrm{m}^{3}\right)$ & $f$ & $c(\mathrm{MPa})$ \\
\hline Rock mass of type II & 21 & 0.25 & 28 & 1.35 & 2 \\
\hline Rock mass of type III1 & 11.5 & 0.25 & 28 & 1.07 & 1.5 \\
\hline Rock mass of type III2 & 6.5 & 0.3 & 28 & 1.02 & 0.9 \\
\hline Rock mass of type III2 (riverbed) & 10 & 0.3 & 28 & 1.02 & 0.9 \\
\hline Rock mass of type IV1 & 3 & 0.35 & 27.5 & 0.7 & 0.6 \\
\hline Rock mass of type IV2 & 2 & 0.35 & 27.5 & 0.6 & 0.4 \\
\hline Rock mass of type V1 & 0.375 & 0.35 & 27.5 & 0.3 & 0.02 \\
\hline $\mathrm{f} 2$ & 0.375 & 0.35 & 26 & 0.3 & 0.02 \\
\hline f18 & 0.375 & 0.35 & 26 & 0.3 & 0.02 \\
\hline f5 & 0.375 & 0.35 & 26 & 0.3 & 0.02 \\
\hline f5 grouting & 0.5 & 0.35 & 26 & 0.3 & 0.02 \\
\hline f5 adit, inclined shaft and seepage treatment inclined shaft & 21 & 0.167 & 24 & 1.35 & 2 \\
\hline f8 & 0.375 & 0.35 & 26 & 0.3 & 0.02 \\
\hline f42-9 & 0.375 & 0.35 & 26 & 0.3 & 0.02 \\
\hline f42-9 antishear cavity & 21 & 0.167 & 24 & 1.35 & 2 \\
\hline f13 & 0.375 & 0.35 & 26 & 0.3 & 0.02 \\
\hline f14 & 0.375 & 0.35 & 26 & 0.3 & 0.02 \\
\hline f14 adit, inclined shaft and seepage treatment inclined shaft & 21 & 0.167 & 24 & 1.35 & 2 \\
\hline $\mathrm{X}($ above $1680 \mathrm{~m})$ & 2 & 0.35 & 27.5 & 0.6 & 0.4 \\
\hline X (below 1680 m) & 6.5 & 0.3 & 28 & 1.02 & 0.6 \\
\hline X grouting & 4 & 0.35 & 27.5 & 0.6 & 0.4 \\
\hline $\mathrm{X}$ adit, inclined shaft and seepage treatment inclined shaft & 21 & 0.167 & 24 & 1.35 & 2 \\
\hline
\end{tabular}

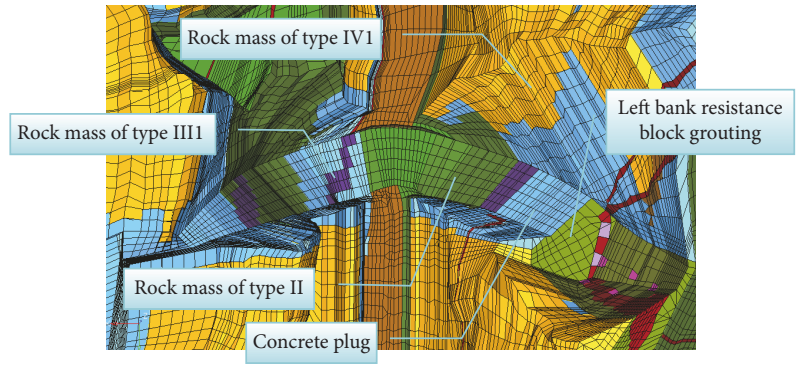

FIgURE 5: Material partition of the dam foundation of the finite element model.

suggestion values of deformation modulus and strength. Table 1 presents the geological suggestion mean values of rock groups and structural surfaces.

After the stimulation of the dam body construction and the crown filling, the overload analysis is carried out by gradually increasing the water unit weight of upstream water pressure. The increment is set to 1.0 times the water unit weight. The FEM computation does not converge when the overload coefficient reaches 9.0. Figure 6 illustrates the yield zone volume ratio-overload coefficient curve. Figure 7 depicts the radial displacement at the different heights of the crown cantilever section.

3.2. Determination of Potential Slide Surfaces. The potential slide surfaces can be determined according to the yield zone connection in the finite element results. In this case, the crack

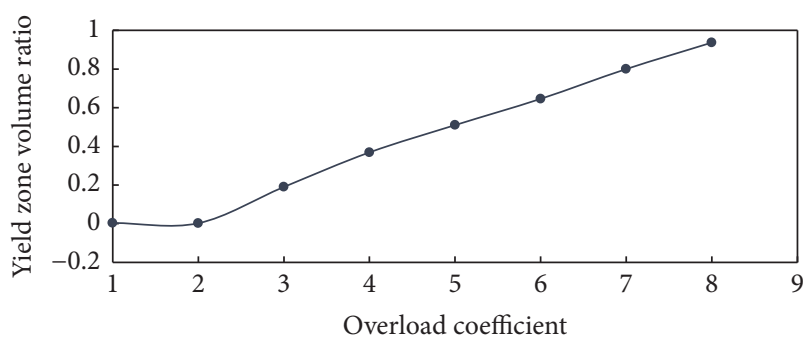

FIGURE 6: Yield zone volume ratio-overload coefficient curve.

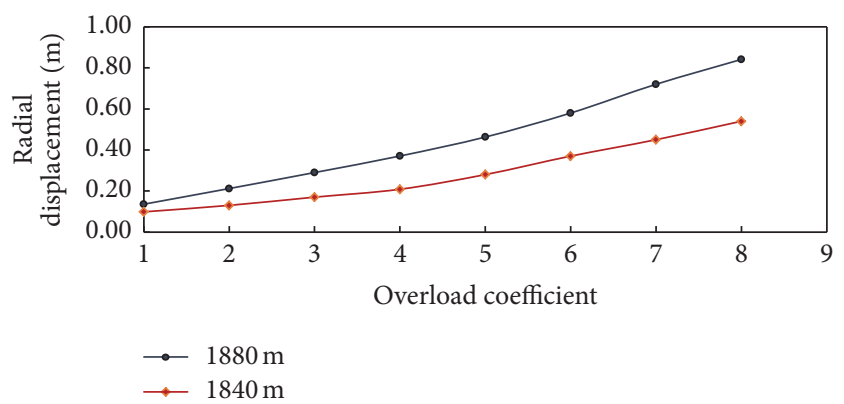

FIgURE 7: Radial displacement at the different heights of the crown cantilever section.

belt near the upstream side of the dam foundation surface is regarded as the upstream slide surface. The side slide surface and the bottom slide surface are determined as follows. 


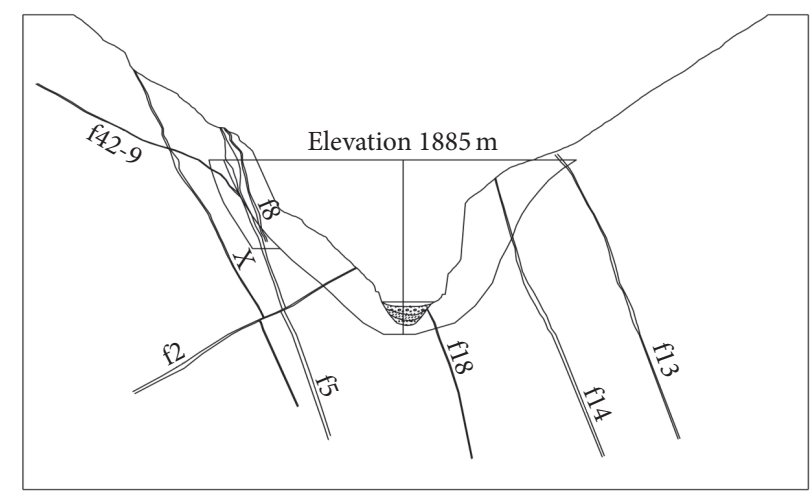

Figure 8: Main faults and dikes (dam axis section).

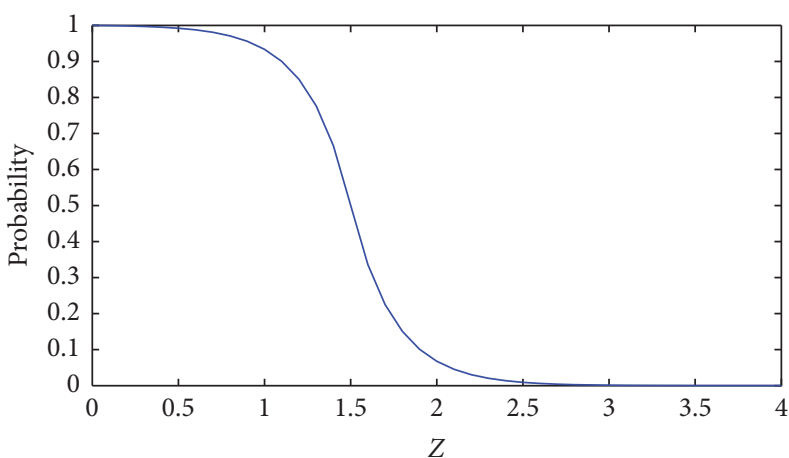

(a) $f(Z)$ of hazard point model

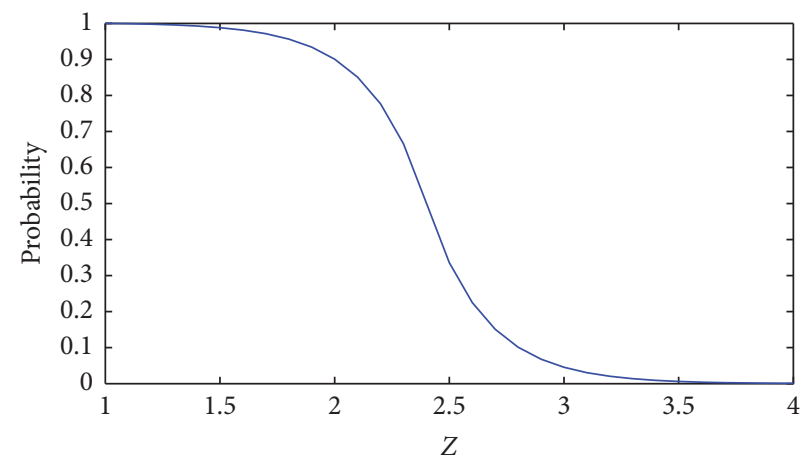

(b) $f(Z)$ of hazard surface model

FIGURE 9: Uncertainty instability failure criterion cumulative distribution functions.

Figure 8 exhibits the main faults and dikes. The weak structure surfaces on the left bank are faults f2, f5, f8, and f429 as well as the macular dike (X). The finite element results verify that the main yield zones are faults $\mathrm{f} 2$ and $\mathrm{f} 5$. Therefore, the following three slide surface groups are selected: (1) f2 fault ( $1660 \mathrm{~m}$ in elevation) considered the bottom slide surface, $\mathrm{f} 5$ fault regarded as the side slide surface, and the normal water level $(1885 \mathrm{~m})$ considered the top elevation of the slide block; (2) f2 fault (1660 $\mathrm{m}$ in elevation) regarded as the bottom slide surface, $\mathrm{f} 5$ fault considered the side slide surface, and $1740 \mathrm{~m}$ regarded as the top elevation of the slide block; as well as (3) $1740 \mathrm{~m}$ considered the bottom slide surface, f5 fault regarded as the side slide surface, and the normal water level $(1885 \mathrm{~m})$ considered the top elevation of the slide block.

3.3. Instability Failure Criterion. The uncertainty instability failure criterion distribution function can be obtained by the yield zone area ratio-overload coefficient curve using the maximum entropy method. The finite element results corroborate that the maximum slope of the yield zone area ratio-overload coefficient curve is at $X=2.40$. The hazard point and the surface antislide stability safety coefficient control standard are 1.5 and 2.5, respectively, according to the design code of concrete arch dams. In consideration of code requirement and simulation results, $X_{m}$ in hazard point as well as hazard surface models are regarded as 1.5 and 2.4, respectively, and distance coefficient $\beta_{1}$ is considered 2.0. Figure 9 shows the uncertainty instability failure criterion cumulative distribution functions $[f(Z)]$ of both models.

\subsection{Credibility Instability Risk Ratio}

3.4.1. Hazard Surface Risk Ratio. The main uncertain variables in hazard surface risk ration calculation are seepage pressures $U_{1}$ and $U_{2}$ on slide surfaces, the total weight of slide block $W$, friction coefficient $f_{1}$, cohesion $c_{1}$, and area $A_{1}$ of the side slide surface, as well as friction coefficient $f_{2}$, cohesion $c_{2}$, and area $A_{2}$ of the bottom slide surface. Table 2 shows the type and the parameter value of these variables.

According to the level-set method, MCS is carried out 30000 times with 100 level sets. The credibility fuzzy random responses are generated by plugging the simulation into (5) (Figure 10). On this basis, the cumulative instability failure credibility density function can be obtained (Figure 11). By utilizing (1), the hazard surface instability risk ratios of the tree cases are $7.4 \times 10^{-6}, 2.5 \times 10^{-7}$, and 0 , respectively.

3.4.2. Hazard Point Instability Risk Ratio. Unlike the hazard surface risk ratio, the stability state function in hazard point risk ratio calculation uses the Mohr-Coulomb formula given in Section 2.2, of which $\sigma_{n i}$ and $\tau_{t i}$ are determined by finite 
TABLE 2: Type and parameter value of main variables in the hazard surface model.

\begin{tabular}{|c|c|c|c|}
\hline Variable & Type & Distribution & Parameter value \\
\hline Upstream water level $H(\mathrm{~m})$ & Random & Normal & $\mu_{H}=1880, \sigma_{H}=0.6$ \\
\hline Rock unit weight of the wedge $\gamma_{r}\left(\mathrm{kN} / \mathrm{m}^{3}\right)$ & Random & Normal & $\mu_{\gamma_{r}}=28.0, \sigma_{\gamma_{r}}=0.5$ \\
\hline Friction coefficient of bottom surface $1740 \mathrm{~m} f_{b}$ & Fuzzy & Triangular & {$[0.9,1,1.1]$} \\
\hline Friction coefficient of fault $\mathrm{f} 2 f_{\mathrm{f} 2}$ & Random & Normal & $\mu_{f_{\mathrm{f} 2}}=0.3, V_{f_{\mathrm{f} 2}}=0.18$ \\
\hline Friction coefficient of fault $\mathrm{f} 5 f_{\mathrm{f} 5}$ & Random & Normal & $\mu_{f_{\mathrm{f} 5}}=0.3, V_{f_{\mathrm{f} 5}}=0.18$ \\
\hline Cohesion of bottom surface $1740 \mathrm{~m} c_{b}(\mathrm{MPa})$ & Fuzzy & Triangular & {$[0.8,0.9,1.0]$} \\
\hline Cohesion of fault $\mathrm{f} 2 c_{\mathrm{f} 2}(\mathrm{MPa})$ & Random & Normal & $\mu_{c_{\mathrm{f} 2}}=0.02, V_{c_{\mathrm{f} 2}}=0.25$ \\
\hline Cohesion of fault $\mathrm{f} 5 c_{\mathrm{f} 5}(\mathrm{MPa})$ & Random & Normal & $\mu_{c_{f 5}}=0.02, V_{c_{f 5}}=0.25$ \\
\hline Side surface area of case $1 A_{1}^{(1)}\left(\mathrm{m}^{2}\right)$ & Fuzzy & Triangular & {$\left[\begin{array}{lll}65252 & 65475 & 65702\end{array}\right]$} \\
\hline Bottom surface area of case $1 A_{2}^{(1)}\left(\mathrm{m}^{2}\right)$ & Fuzzy & Triangular & {$\left[\begin{array}{lll}36246 & 37248 & 38359\end{array}\right]$} \\
\hline Side surface area of case $2 A_{1}^{(2)}\left(\mathrm{m}^{2}\right)$ & Fuzzy & Triangular & {$\left[\begin{array}{lll}41524 & 41666 & 41810\end{array}\right]$} \\
\hline Bottom surface area of case $2 A_{2}^{(2)}\left(\mathrm{m}^{2}\right)$ & Fuzzy & Triangular & {$\left[\begin{array}{lll}36246 & 37248 & 38359\end{array}\right]$} \\
\hline Side surface area of case $3 A_{1}^{(3)}\left(\mathrm{m}^{2}\right)$ & Fuzzy & Triangular & {$\left[\begin{array}{lll}23728 & 23809 & 23892\end{array}\right]$} \\
\hline Bottom surface area of case $3 A_{2}{ }^{(3)}\left(\mathrm{m}^{2}\right)$ & Fuzzy & Triangular & {$\left[\begin{array}{lll}13180 & 13545 & 13949\end{array}\right]$} \\
\hline
\end{tabular}

Note. $\mu_{H}$ and $\sigma_{H}$ are the mean value and the standard deviation of variable $H$, respectively; $X=[l, m, r]$ is a triangular fuzzy number, where $l$ and $r$ are the minimum limit and the maximum limit of variable $X$, respectively, when cut set level $\alpha=0$ and $m$ is the most possible value of variable $X$.

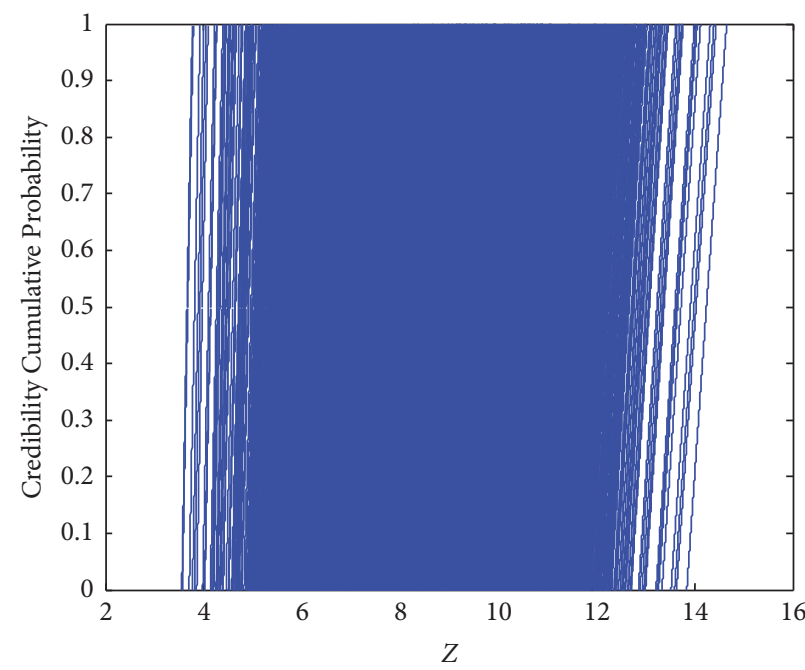

(a) Case 1

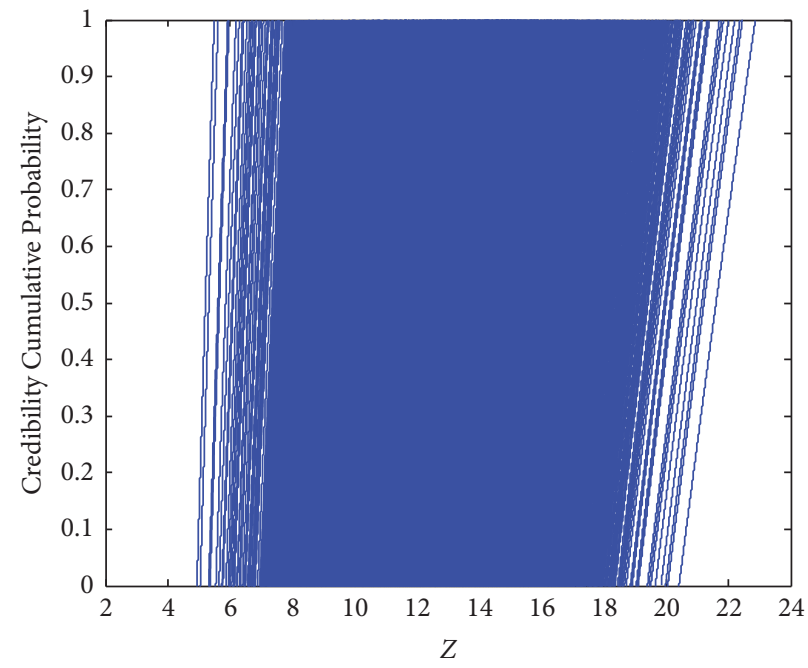

(b) Case 2

FIGURE 10: Fuzzy random responses of the risk ratio model under different cases.

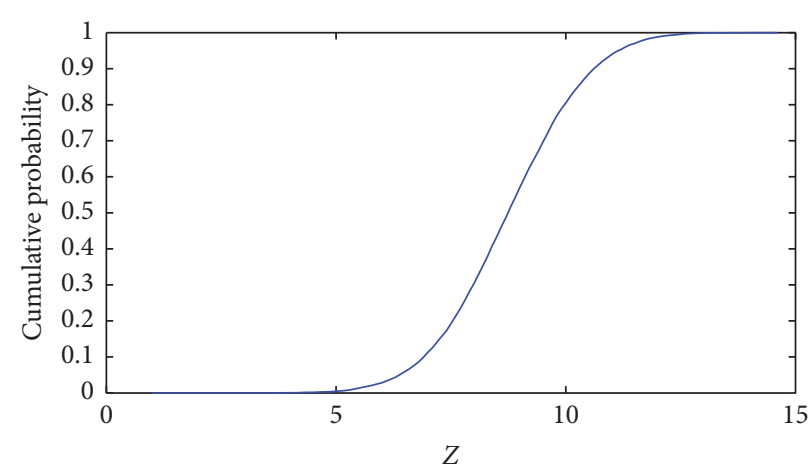

(a) Case 1

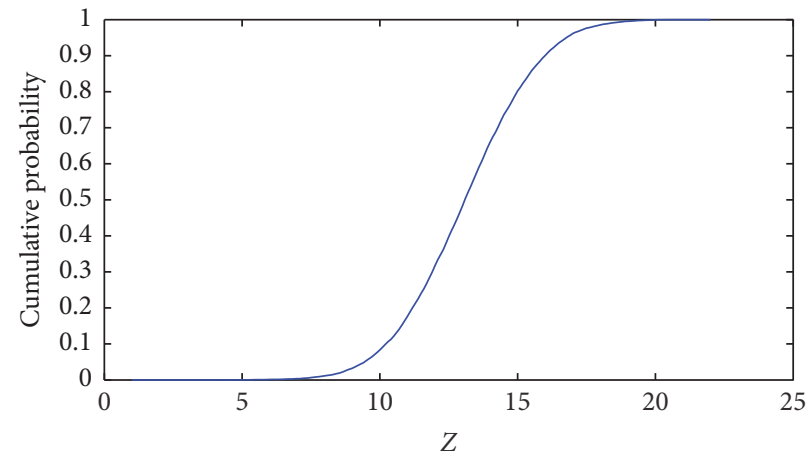

(b) Case 2

FIGURE 11: Cumulative instability failure credibility density function. 
TABLE 3: Parameter values of variables in the hazard point risk model.

\begin{tabular}{|c|c|c|c|}
\hline Variable & Mean value & Coefficient of variation & Scale of fluctuation (m) \\
\hline Friction coefficient of fault $\mathrm{f} 2 f_{\mathrm{f} 2}^{\prime}$ & 0.3 & 0.18 & {$\left[\begin{array}{lll}30 & 60 & 80\end{array}\right]$} \\
\hline Friction coefficient of fault f5 $f_{\mathrm{f} 5}^{\prime}$ & 0.3 & 0.18 & {$\left[\begin{array}{lll}30 & 60 & 80\end{array}\right]$} \\
\hline Cohesion of fault $\mathrm{f} 2 c_{\mathrm{f} 2}^{\prime}(\mathrm{MPa})$ & 0.02 & 0.25 & {$\left[\begin{array}{lll}30 & 60 & 80\end{array}\right]$} \\
\hline Cohesion of fault $\mathrm{f} 5 c_{\mathrm{f} 5}^{\prime}(\mathrm{MPa})$ & 0.02 & 0.25 & {$\left[\begin{array}{lll}30 & 60 & 80\end{array}\right]$} \\
\hline
\end{tabular}

Note. $\left[\begin{array}{lll}30 & 60 & 80\end{array}\right]$ is a triangular distribution.

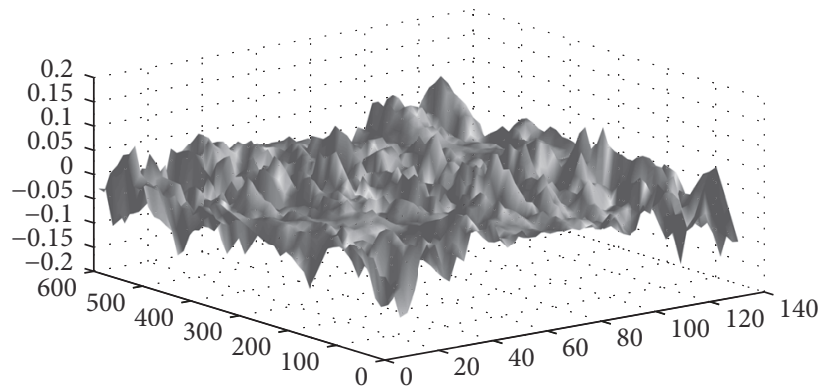

(a) $\theta=30$

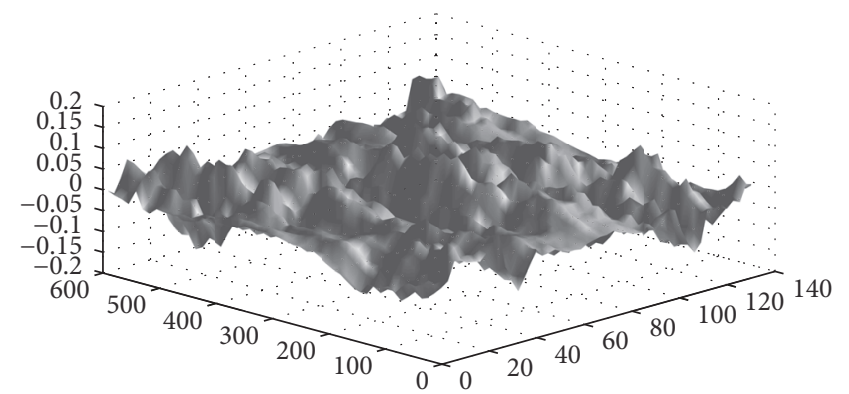

(c) $\theta=60$

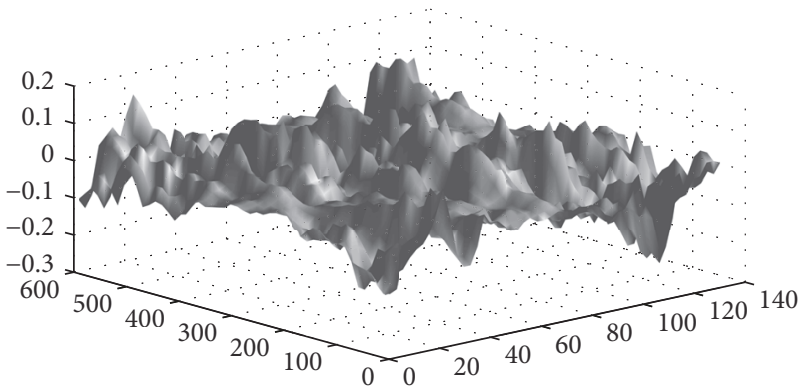

(b) $\theta=50$

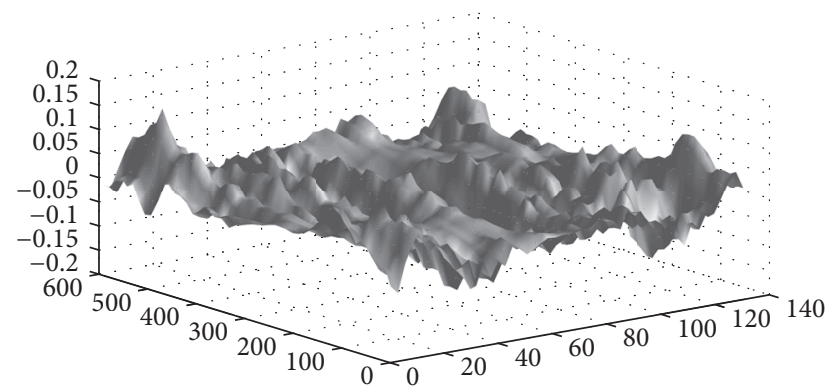

(d) $\theta=80$

FIGURE 12: Surface map of 2D GRFs with zero mean and the unit coefficient of variation.

element results and material properties $f_{1}, c_{1}, f_{2}$, and $c_{2}$ are regarded as random variables with spatial variability. Table 3 exhibits the parameter values of variables in the hazard point risk model.

Gaussian random fields are generated through the FFT technique. Figure 12 depicts the GRFs for the different scales of fluctuation. Taking 100 level sets, the GRF simulation is repeated 30000 times for parameters on each slide surface. The credibility fuzzy random responses are generated by plugging the simulation and FEM stress results into (4). Figure 13 exhibits the cumulative instability failure credibility density function. The hazard point instability risk ratios of the three computing groups are $1.2 \times 10^{-5}, 5.6 \times 10^{-6}$, and $3.2 \times$ $10^{-9}$, respectively.

The computing results assert that the hazard point instability risk ratio is slightly larger than the hazard surface instability risk ratio. Both of them have not exceeded the acceptable risk ratio $\left(1 \times 10^{-4}\right)$.

\section{Conclusion}

In this paper, on the basis of the identification of influence factors in high arch dam abutment instability risk analysis,

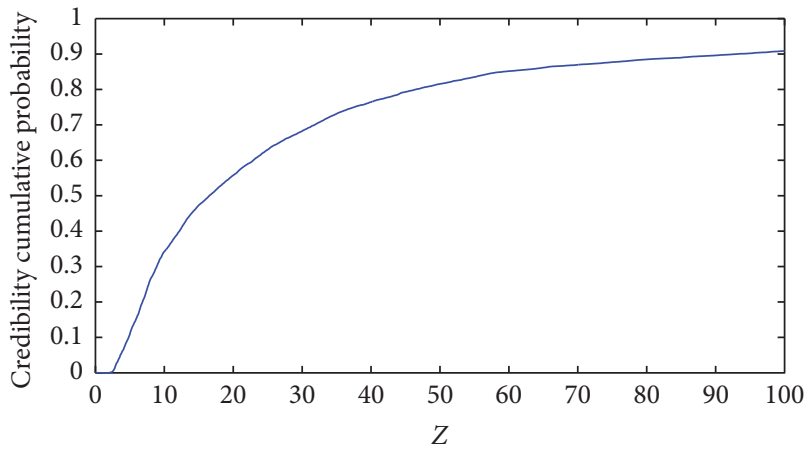

FIGURE 13: Cumulative instability failure credibility density function of Case 1.

fuzzy random mathematics is used to reflect the multiple uncertainties associated with the risk analysis model, a GRF is applied to simulating spatial variability, the fuzzy instability criterion is derived from maximum entropy theory, and the hazard point risk as well as hazard surface risk models of high arch dam abutment instability are proposed using MCS. Conclusions are as follows. 
(1) On the basis of the catastrophe criterion, the uncertainty instability failure criterion distribution function $[f(Z)]$ is derived from the maximum entropy principle in Shannon's entropy theory.

(2) With the use of credibility mathematics, uncertainty identification is carried out on influence factors, such as load, material property, and geometrical size. On this basis, each variable is assigned a probability or a possibility distribution. The hazard point risk ratio and hazard surface instability risk ratio models are proposed using credibility theory.

(3) Gaussian random fields are generated through the FFT technique to represent the spatial variability of geological parameters. The risk analysis method combining fuzzy random response and MCS is proposed.

\section{Conflicts of Interest}

The authors declare that they have no conflicts of interest regarding the publication of this paper.

\section{Acknowledgments}

This research was supported by National Natural Science Foundation of China (Grants nos. 41323001, 51479054, 51579086, 51379068, 51579083, and 51579085), National Key Research and Development Project (2016YFC0401601), Jiangsu Natural Science Foundation (Grant no. BK20140039), Research Fund for the Doctoral Program of Higher Education of China (Grant no. 20130094110010), Project Funded by the Priority Academic Program Development of Jiangsu Higher Education Institutions (Grant no. YS11001), and Central University Basic Research Project (Grant no. 2015B20714).

\section{References}

[1] R. Wang, "Review of construction achievements and technological development of super-high arch dam in China," Advances in Science \& Technology of Water Resources, 2015.

[2] Z. R. Wu, Safety Monitoring Theory And Its Application of Hydraulic Structures, Beijing: Higher Education, 2003.

[3] C. Bernier, J. E. Padgett, J. Proulx, and P. Paultre, "Seismic fragility of concrete gravity dams with spatial variation of angle of friction: Case study," Journal of Structural Engineering, vol. 142, article 05015002, no. 5, 2016.

[4] A. Krounis, F. Johansson, and S. Larsson, "Effects of spatial variation in cohesion over the concrete-rock interface on dam sliding stability," Journal of Rock Mechanics and Geotechnical Engineering, vol. 7, no. 6, pp. 659-667, 2015.

[5] A. Krounis, F. Johansson, J. Spross, and S. Larsson, "Influence of Cohesive Strength in Probabilistic Sliding Stability Reassessment of Concrete Dams," Journal of Geotechnical \& Geoenvironmental Engineering, no. article 04016094, 2016.

[6] G. Shao, J. Q. Zhuo, and Zhang., "Research on analysis method and criterion of rockmass stability," Chinese Journal of Rock Mechanics \& Engineering, vol. 22, no. 5, pp. 691-696, 2003.

[7] Q. Yang, Y. Liu, Y. Chen, and W. Zhou, "Deformation reinforcement theory and its application to high arch dams," Science in China Series E: Technological Sciences, vol. 51, no. S2, pp. 32-47, 2008.
[8] X. Yu, Y. Zhou, and S. Peng, "Stability analyses of dam abutments by 3D elasto-plastic finite-element method: A case study of Houhe gravity-arch dam in China," International Journal of Rock Mechanics and Mining Sciences, vol. 42, no. 3, pp. 415-430, 2005.

[9] R. Wang, L. W. Peng, and Zhou., "Study on cracking and stability problems of high arch dams on complicated foundations," Chinese Journal of Rock Mechanics \& Engineering, vol. 26, no. 10, pp. 1951-1958, 2007.

[10] S. Song, B. Xiang, J. Yang, and X. Feng, "Stability analysis and reinforcement design of high and steep slopes with complex geology in abutment of Jinping I hydropower station," Chinese Journal of Rock Mechanics \& Engineering, vol. 29, no. 3, pp. 442458, 2010.

[11] Q. W. Ren, X. D. Qian, Y. Zhao, and S. H. Fu, "Methods for analyzing sliding resistance stability along the base surface of high arch dam," Journal of Hydraulic Engineering, vol. 2, pp. 1-7, 2002.

[12] X. Li and B. Liu, Chance Measure for Hybrid Events with Fuzziness and Randomness, Chance measure for hybrid events with fuzziness and randomness, 2008.

[13] X. Li and B. Liu, "Foundation of credibilistic logic," Fuzzy Optimization \& Decision Making, vol. 8, no. 1, pp. 91-102, 2009.

[14] B. Zhang and H. Chen, "Analysis on abutment aseismatic stability by using finite element and rigid body limit equilibrium method," Chinese Journal of Rock Mechanics \& Engineering, vol. 20, no. 5, pp. 665-670, 2001.

[15] Design Specification for Concrete Arch Dams SL282-2003, China Water Power Press, 2015.

[16] R. Salgado and D. Kim, "Reliability analysis of load and resistance factor design of slopes," Journal of Geotechnical \& Geoenvironmental Engineering, vol. 140, no. 1, pp. 57-73, 2014.

[17] G. A. Fenton and D. V. Griffiths, Risk Assessment in Geotechnical Engineering, John Wiley \& Sons.

[18] B. Chen, C. Gu, T. Bao, B. Wu, and H. Su, "Failure analysis method of concrete arch dam based on elastic strain energy criterion," Engineering Failure Analysis, vol. 60, pp. 363-373, 2016.

[19] R. M. Gray, Entropy and Information Theory, Science Press, 2012.

[20] C. Baudrit, D. Dubois, and D. Guyonnet, "Joint propagation and exploitation of probabilistic and possibilistic information in risk assessment," IEEE Transactions on Fuzzy Systems, vol. 14, no. 5, pp. 593-608, 2006. 


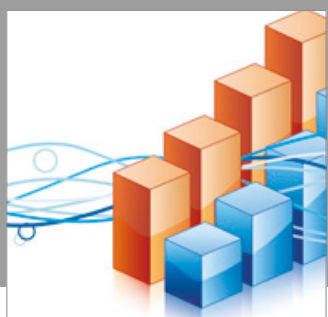

Advances in

Operations Research

vatersals

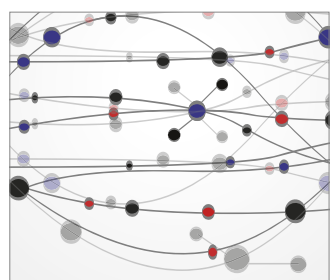

\section{The Scientific} World Journal
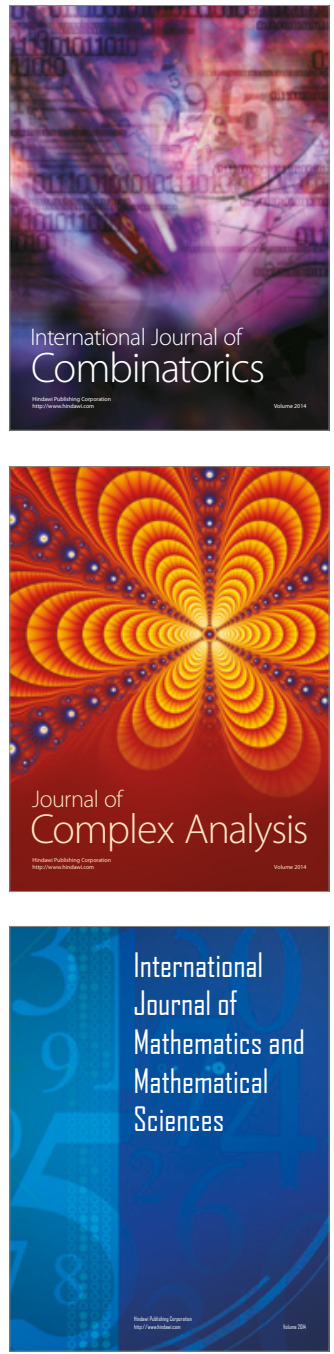
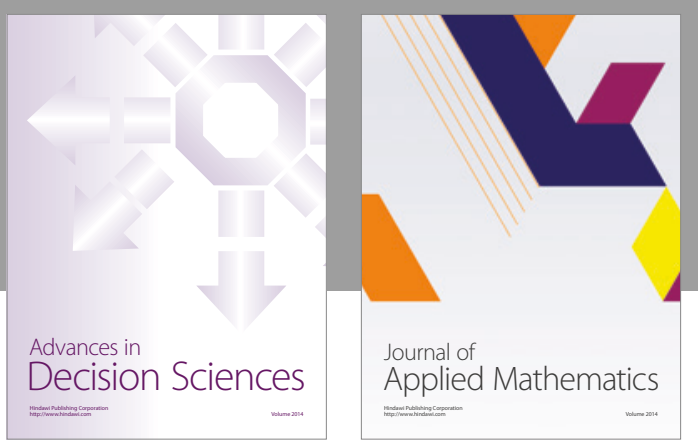

Algebra

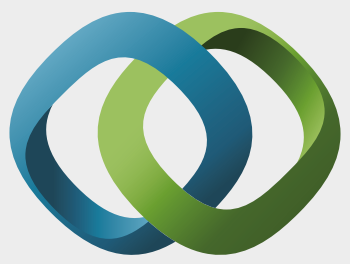

\section{Hindawi}

Submit your manuscripts at

https://www.hindawi.com
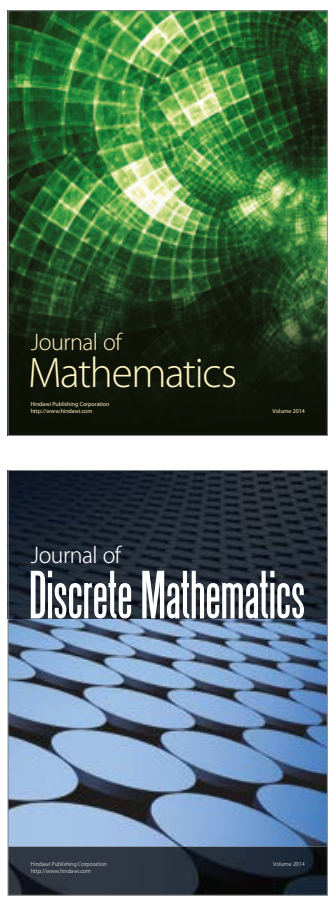

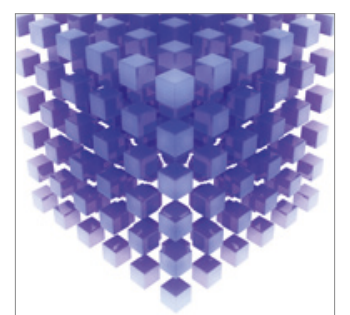

Mathematical Problems in Engineering
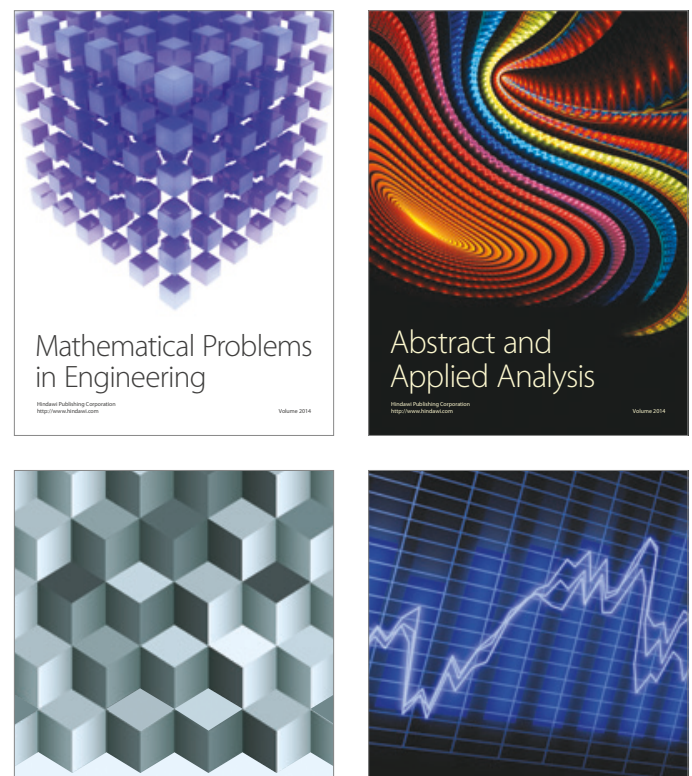

Journal of

Function Spaces

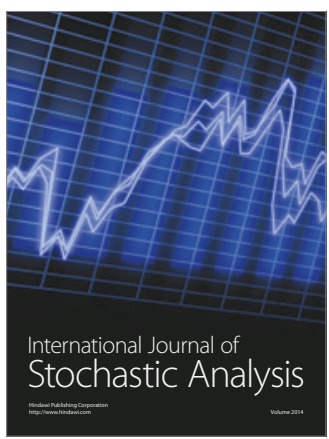

Probability and Statistics
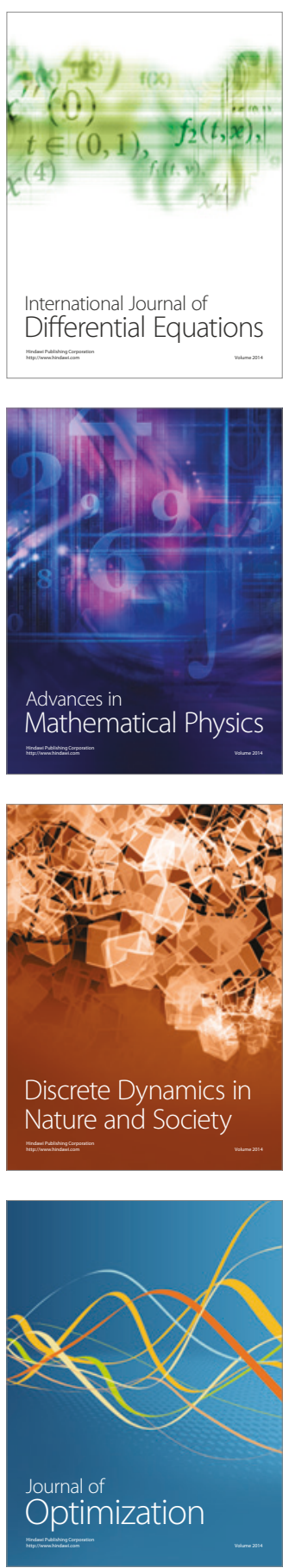